\title{
“ALARME DE INCÊNDIO": MICHAEL LÖWY E A CRÍTICA ECOSSOCIALISTA DA CIVILIZAÇÃO CAPITALISTA MODERNA
}

\author{
"FIRE ALARM:" MICHAEL LÖWY AND THE ECOSOCIALIST CRITIQUE OF THE MODERN \\ CAPITALIST CIVILIZATION
}

Fabio Mascaro Querido ${ }^{1}$

Resumo A emergência da crise ecológica, como sintoma mais nítido de uma verdadeira crise civilizatória, impôs novos desafios ao pensamento crítico e, em especial, ao marxismo. Partindo desse pressuposto, o objetivo deste artigo é apresentar a defesa de Michael Löwy de uma radicalização ecossocialista da crítica marxista da modernidade, tarefa para a qual a grande recusa de Walter Benjamin das ideologias do progresso é uma das fontes decisivas de inspiração. Para Michael Löwy, a ruptura com as ideologias do progresso e com o paradigma civilizatório capitalista moderno é uma condição indispensável para a atualização ecossocialista do marxismo.

Palavras-chave Michael Löwy; ecossocialismo; crítico do progresso; crítica da modernidade.
Abstract The emergence of the ecological crisis as a clearer symptom of a true civilizatory crisis has imposed new challenges to critical thought and, in particular, to Marxism. Based on this assumption, this article aims to present Michael Löwy's defense of an ecosocialist radicalization of the Marxist critique of modernity, a task for which Walter Benjamin's great refusal of the ideologies of progress is one of the critical sources of inspiration. To Michael Löwy, breaking away from the ideologies of progress and from the modern capitalistic civilizatory paradigm is a prerequisite for the ecosocialist updating of Marxism.

Keywords Michael Löwy; ecosocialism; critical of progress; critique of modernity. 
A história nada sabe da má infinitude na imagem dos dois combatentes eternamente lutando. O verdadeiro politico só calcula em termos de prazos. E se a eliminação da burguesia não estiver efetivada até um momento quase calculável do desenvolvimento econômico e técnico, tudo está perdido. Antes que a centelha chegue à dinamite, é preciso que o pavio que queima seja cortado.

(Walter Benjamin, 2000, p. 45-46)

\section{Crise civilizatória e 'atualização' teórica}

O destino de uma teoria crítica depende, como se sabe, da capacidade por ela demonstrada de 'acompanhar' o dinamismo do seu objeto, no caso, do capitalismo em seu conjunto, em suas múltiplas esferas, temporalidades e formas de legitimação simbólica. Uma teoria crítica só pode permanecer efetivamente crítica se conseguir lograr uma 'atualização' permanente, à luz das transformações do sistema e de suas ressonâncias nas formas de resistências e lutas políticas, sociais e culturais. É por isso mesmo que, antes de tudo, uma teoria crítica deve ser crítica em relação a si própria, ou melhor, em relação à sua própria capacidade de não se deixar petrificar num sistema teórico fechado, invalidando a possibilidade de recomposição constante de uma teoria da (e não para a) práxis, cuja pretensão de verdade é tão histórica quanto seu 'objeto'.

Já há algum tempo, três ou quatro décadas, tornou-se nítido o caráter eminentemente destrutivo do modelo produtivo e civilizatório exacerbado no século XX tanto nos países declaradamente capitalistas quanto nos Estados pós-capitalistas do Leste Europeu. Desde então, o que parecia ser tão somente o resultado de um excesso passageiro e historicamente contornável, revelou ser, na verdade, a emergência de uma verdadeira crise do paradigma civilizatório estabelecido: o capitalismo moderno. Nesse contexto, o surgimento da chamada 'crise ecológica' foi apenas o sintoma mais nítido de uma crise múltipla - econômica, social, política e cultural -, sobredeterminada pelo avanço da mercantilização da vida social e da natureza em sua totalidade. Nas palavras de Michael Löwy:

As atuais crises econômica e ecológica são parte de uma conjuntura histórica mais geral: estamos enfrentando uma crise do presente modelo de civilização, a civilização ocidental moderna capitalista/industrial, baseada na expansão e acumulação ilimitada de capital, na 'mercantilização de tudo', na intensa exploração do trabalho e da natureza, no individualismo e competição brutais, e na destruição 
massiva do meio ambiente. A crescente ameaça de ruptura do equilíbrio ecológico aponta para um cenário catastrófico - o aquecimento global - que coloca em perigo a sobrevivência mesma da espécie humana. Enfrentamos uma crise de civilização que demanda uma transformação radical (Löwy, 2009, p. 50).

Diante de evidências de tamanha magnitude, é forçoso reconhecer a necessidade inelutável de uma reavaliação da crítica ao capitalismo. A partir desses desafios do presente, a herança dos clássicos - que não é um material inerte, morto - deve ser atualizada, ao preço da manutenção de suas referências para a recomposição das lutas sociais das classes subalternas na era da 'mundialização' capitalista. Sob um horizonte de poucas certezas, cerceado pela desconfiança geral, o momento é certamente paradoxal: de um lado, há o esgotamento das forças 'anticapitalistas' tradicionais ('comunistas' e/ou social-democratas) e o simultâneo triunfo progressivo da ofensiva neoliberal parecem, de fato, anunciar o fim das grandes esperanças revolucionárias; mas, de outro lado, esse declínio histórico, embora sob o signo da derrota do movimento operário, abre uma interessante chance histórica para a atualização teórica do pensamento crítico e, em especial, do marxismo.

Sem temer o cometimento (necessário) de 'pecados' e 'heresias', tornase possível efetuar uma releitura dos autores clássicos ou marginais do pensamento crítico com base nos imperativos teóricos e políticos do presente. E, como sabemos, toda reinterpretação é sempre seletiva e, portanto, tão polêmica quanto necessária. Assim, o objetivo deste artigo é apresentar e, em alguma medida, analisar as premissas teóricas constituídas em torno da questão ecossocialista, particularmente na forma com que a temática é articulada na obra de Michael Löwy. Tanto a questão ecossocialista, desde a década de 1970, quanto os pressupostos teóricos da crítica da civilização capitalista moderna defendida por Michael Löwy constituem formas polêmicas de releitura seletiva do legado da tradição do pensamento revolucionário a partir do contexto de crise civilizatória. Novas questões e novos desafios emergem, exigindo a potencialização de alguns aspectos da teoria, assim como o abandono consciente de outros.

\section{Crítica do progresso e da modernidade: a renovação ecossocialista do marxismo em Michael Löwy}

A emergência da perspectiva ecossocialista é praticamente contemporânea ao surgimento vertiginoso da crise ecológica na agenda política e social. Acima de tudo, ela nasceu, nas últimas quatro décadas, a partir de debates e obras de diversos intelectuais que contribuíram para a formação de uma "corrente de pensamento e de ação" (Löwy, 2005, p. 49) capaz de demarcar 
posição em defesa da renovação 'ecológica' do marxismo. Destacam-se, dentre esses intelectuais, os nomes de Manuel Sacristán, Raymond Williams, Rudolf Bahro e André Gorz, além dos mais contemporâneos James O'Connor (atual diretor da revista Capitalism, Nature, Socialism), Barry Commoner, John Bellamy Foster, John Clark e Joel Kovel, nos Estados Unidos; Francisco Fernández Buey, Jorge Riechmann e Joan Martínez Alier, na Espanha; Jean-Paul Deléage, Michael Löwy e Jean-Marie Harribey, na França; e Elmar Altvater e Frieder Otto Wolf, na Alemanha.

Mais recentemente, Michael Löwy e Joel Kovel foram os responsáveis pela redação dos dois manifestos internacionais do ecossocialismo, ${ }^{2}$ que expõem com clareza os princípios programáticos básicos do 'movimento'. Os dois intelectuais ocupam lugar de destaque na caracterização teórica e política do assim chamado ecossocialismo no cenário intelectual contemporâneo. No caso de Michael Löwy, além do mais, a inserção nos debates em defesa do ecossocialismo é uma espécie de condensação de toda a sua trajetória intelectual, marcada pela busca incessante das afinidades eletivas entre diferentes correntes de pensamento, a fim de oxigenar a crítica marxista da modernidade - premissa mais que necessária para a elaboração de uma perspectiva ecossocialista.

Retomando o argumento de diversos autores, Michael Löwy define genericamente o ecossocialismo como uma corrente de pensamento e de ação que engloba "as teorias e os movimentos que aspiram a subordinar o valor de troca ao valor de uso, organizando a produção em função das necessidades sociais e das exigências da proteção do meio ambiente" (Löwy, 2005, p. 49). Joel Kovel, na mesma perspectiva, anuncia o ecossocialismo “como uma luta pelo valor de uso e, através do valor de uso realizado, pelo valor intrínseco. Isto significa que é uma luta pelo lado qualitativo das coisas"3 (Kovel, 2005, p. 204; nossa tradução). Predomínio do valor de uso e crítica do fetichismo da mercadoria, eis a articulação necessária à concepção e à vivência prática de uma temporalidade qualitativa bem diferente dos imperativos do tempo que reduz o homem à condição de sua carcaça, como disse Marx certa vez.

É com essa perspectiva ampla que se espera forjar um espaço de convergência entre os movimentos ecológicos e um marxismo renovado - atento à intensificação da lógica destrutiva do capitalismo. Composto basicamente por intelectuais mais ou menos próximos ao marxismo, o ecossocialismo é um parâmetro teórico-político a partir do qual se estabelece a possibilidade de um diálogo crítico com as demandas e reflexões dos movimentos ecológicos. De outro ângulo, é também uma estratégia de atualização teórica interna ao pensamento crítico, em geral, e ao marxismo, em particular. Se o ecossocialismo reivindica as "aquisições fundamentais do marxismo", ele não hesita em se livrar "das suas escórias produtivistas" (Löwy, 2005, p. 49). 
Trata-se, então, de uma concepção renovada do socialismo que faz um acerto de contas radical com a herança do socialismo burocrático do Leste Europeu - responsável por níveis de devastação ecológica semelhantes aos das sociedades capitalistas ocidentais -, sem abandonar a perspectiva anticapitalista. Noutras palavras: “o ecossocialismo é mais que o socialismo, tal qual o conhecemos tradicionalmente, mas é também, definitivamente, socialista"4 (Kovel, 2005, p. 205; nossa tradução).

Essa releitura atualizada da tradição socialista passa, entre outras coisas, por uma revisão autocrítica de algumas concepções caras ao marxismo 'clássico', por assim dizer. Um novo diagnóstico de época, numa era de transformações substantivas do modo de funcionamento do sistema (assim como de seus virtuais oponentes), se não implica a fundação de um novo sistema teórico, supõe a necessidade não de apenas mais uma análise concreta da situação concreta, a partir de uma pretensão de verdade já pressuposta e de antemão legitimada, mas de uma reavaliação crítica do próprio instrumental teórico utilizado para a análise dos fenômenos sociais concretos: o marxismo.

De início, radicalizando as intuições de uma Rosa Luxemburg abalada pela guerra ('socialismo ou barbárie'), a retomada de uma visão radicalmente aberta da história permite visualizar as catástrofes que podem originar-se da atual crise ecológica. Em seguida, a construção de uma perspectiva ecossocialista atualiza de forma dramática a exigência benjaminiana, ainda no final da década de 1920, da necessidade de um "materialismo histórico que aniquilou em si a ideia de progresso" (Benjamin, 2006, p. 502). Nessa ruptura com os resquícios de ideologia do progresso que atravessaram correntes importantes do marxismo, encontram-se os alicerces de uma nova crítica dialética da civilização capitalista moderna.

O abandono do culto moderno do progresso significa o reconhecimento do esgotamento de um modelo de transição socialista que, além de evolucionista e devidamente eurocêntrico, não titubeou em 'pegar carona', digamos assim, no 'progresso' impulsionado pelo desenvolvimento capitalista das forças produtivas. 5 À diferença das camadas subalternas pré-modernas, plebeus e camponeses, o movimento operário moderno seria um produto e, em certa medida, um continuador histórico do progresso das forças produtivas após sua libertação do jugo 'anacrônico' das relações de produção. O socialismo, numa célebre metáfora de Marx, seria a locomotiva do progresso na história, num momento em que o capitalismo não poderia mais realizar essa tarefa.

Há alguns anos, Immanuel Wallerstein (2001, p. 83, 84) observou: "se há uma ideia associada ao mundo moderno, é a noção de progresso". A noção de progresso legitimou historicamente a transição do feudalismo para o capitalismo, ou seja, "legitimou que a oposição remanescente à mercantilização 
de tudo fosse destruída e permitiu descartar os aspectos negativos do capitalismo com base na noção de que os benefícios superavam em muito os prejuízos". Logo, diz o autor, "não é surpreendente que os liberais acreditassem no progresso". O mais surpreendente, talvez, é que exatamente o seu oponente ideológico - o marxismo e, de quebra, as classes oprimidas - acreditasse "no progresso com, pelo menos, a mesma paixão". Não aleatoriamente, "ao mesmo tempo em que a ideia de progresso justificava o socialismo, também justificava o capitalismo. Era difícil aclamar o proletariado sem antes prestar homenagens à burguesia". Os exemplos não faltam. E no limite, “a adesão marxista ao modelo evolucionário do progresso tem sido uma enorme armadilha, da qual os socialistas só começaram a desconfiar recentemente, como um elemento da crise ideológica que é parte da crise estrutural global da economia mundial capitalista".

Exatamente por isso, a ruptura com a ideia de progresso impõe igualmente a potencialização da crítica à civilização moderna. E, tanto quanto outros importantes autores, Michael Löwy vem insistindo na necessidade de radicalização da crítica marxista da civilização moderna - condição sine qua non para a formulação de um projeto ecossocialista. Em suas palavras: "o ecossocialismo implica uma radicalização da ruptura com a civilização material capitalista"6 (Löwy, 2003, p. 22; nossa tradução). Ele visa não somente a uma nova sociedade e a um novo modo de produção, mas também a um novo paradigma de civilização (Löwy, 2003, p. 22).

\section{Conflito de temporalidades: o fetichismo mercantil contra a natureza}

Não por acaso, a crítica ao culto do progresso e da civilização capitalista moderna exige a crítica correspondente do aparelho produtivo vigente. $\mathrm{Na}$ contramão da vulgata marxista, que concebe a transformação social como mera supressão - reformista ou revolucionária - das relações sociais de produção, capaz de destruir os obstáculos ao livre desenvolvimento das forças produtivas, um ecossocialismo do século XXI questiona “a própria estrutura do processo de produção" (Löwy, 2005, p. 76). Como observa Löwy, é necessário

(...) aplicar às forças produtivas, de um ponto de vista ecossocialista, o argumento que Marx utilizava a propósito da Comuna de Paris: os trabalhadores não podem se apropriar do aparelho de Estado existente (burguês), e colocá-lo a seu serviço; mais além, tem de quebrá-lo e substituí-lo por outra forma de poder político. O mesmo vale, mutatis mutandis, para o aparelho produtivo capitalista: não pode ser simplesmente apropriado pelos trabalhadores, mas tem que sofrer uma radical 
transformação, em sua tecnologia, em suas fontes de energia, em sua estrutura (Querido, 2009, p. 182).

Trata-se, então, da necessidade de uma reestruturação radical de todo o sistema industrial, entre cujos objetivos encontra-se a

reestruturação radical das necessidades dos homens e uma transformação da relação com os bens de consumo capaz de fazer com que o valor de uso material coloque fim ao regime de troca - enfim, uma transformação social chamada ecossocialismo7 $^{7}$ (Kovel, 2003, p. 153; nossa tradução). ${ }^{8}$

Do ponto de vista mais propriamente teórico, o que garante a unidade e a coerência entre essas análises é uma atualização da crítica marxista do fetichismo mercantil, capaz de revelar, sob a aparência fantasmagórica de um mundo cada vez mais subordinado aos imperativos da forma-mercadoria, os conflitos sociais dos quais pode emanar uma visão de mundo alternativa. Dessa perspectiva, "uma ecologia que ignora ou negligencia o marxismo e sua crítica do fetichismo da mercadoria está condenada a não ser mais do que uma correção dos 'excessos' do produtivismo capitalismo" (Löwy, 2005, p. 38). $\mathrm{Na}$ análise do fetichismo mercantil, podem encontrar-se chaves interpretativas para a crítica da temporalidade subjacente à noção de progresso engendrada pela civilização capitalista moderna, constituindo-se num importante aporte teórico e político para a constituição de uma pers-pectiva ecossocialista.

O tempo do fetichismo mercantil, como demonstrou Lukács em História e consciência de classe, não é senão o tempo do trabalho abstrato. Assim como o produto do trabalho - a mercadoria -, o tempo transforma-se, no capitalismo moderno, numa objetividade reificada, que impõe uma medida abstrata para a organização da vida social como um todo. Numa sociedade caracterizada, entre outras coisas, pela universalização da forma-mercadoria, o tempo abstrato tende a se impor ao homem como uma objetividade que funciona independentemente de seu controle ou vontade imediata, enfim, como uma objetividade reificada. Assim, como disse Lukács, “o tempo perde o seu caráter qualitativo, mutável e fluído; ele se fixa num continuum delimitado com precisão, quantitativamente mensurável" (2003, p. 205). Foi pensando nessa quantificação do tempo - absolutamente necessária ao desenvolvimento do capitalismo - que Marx afirmou que "o tempo é tudo, o homem não é nada; é quando muito a carcaça do tempo" (Marx, 2001, p. 49).

Hoje em dia, com a emergência de certa 'consciência ecológica', não é difícil notar o quanto a temporalidade abstrata do capitalismo é visceralmente contraditória com os ritmos e temporalidades específicos da natureza, e mesmo daquilo que há de natural no humano. Há uma espécie de divórcio, portanto, entre duas temporalidades heterogêneas que as tendências 
do desenvolvimento capitalista tornaram contraditórias, criando um conflito de temporalidades: "uma temporalidade econômica, ritmada pela reprodução do capital e da força de trabalho; uma temporalidade ecológica, regida pela estocagem e o dispêndio de energia, que é também tempo estocado" (Bensaïd, 1999, p. 478).

Ainda na década de 1930, Walter Benjamin já havia assinalado o caráter destrutivo da temporalidade abstrata subjacente às diversas formas de ideologias do progresso e da civilização moderna. Segundo observa Michael Löwy (2005, p. 43), Walter Benjamin foi um dos primeiros marxistas a questionar o sentido destrutivo do paradigma tecnológico e econômico da civilização industrial moderna. Por essa razão, o filósofo sempre desconfiou do ímpeto capitalista pela dominação da natureza, bem como das apologias do trabalho abstrato e do desenvolvimento técnico-industrial que estão na sua base. Nas "teses sobre o conceito de história", de 1940, Benjamin denuncia o conceito de trabalho cujo interesse "se dirige apenas aos progressos na dominação da natureza, e não aos retrocessos na organização da sociedade" (1994, p. 228), recorrendo aos sonhos de Fourier para defender uma nova concepção de trabalho, baseada num novo pacto entre o homem e seu meio ambiente, um "tipo de trabalho que, longe de explorar a natureza, libera as criações (...) em seu ventre" (Benjamin, 1994, p. 228).

Como demonstra Michael Löwy (2005, p. 105), a glorificação do trabalho industrial como um fim em si do progresso técnico significava, para Benjamin, a constituição de uma concepção da natureza como matéria-prima de exploração ilimitada. O culto ao progresso técnico, ancorado numa secularização da apologia protestante do trabalho (que muito influenciou as concepções da social-democracia alemã, um dos alvos da crítica benjaminiana), ignora o aspecto destrutivo desse desenvolvimento (Benjamin, 2000, p. 184). Para Benjamin, "nada foi mais corruptor para a classe operária alemã que a opinião de que ela nadava com a corrente. O desenvolvimento técnico era visto como o declive da corrente, na qual supunha estar nadando" (Benjamin, 1994, p. 227).

Ora, mais do que no tempo de Benjamin, um marxismo ecologicamente atualizado sabe que, de fato, a "corrente" do "desenvolvimento técnico", muito longe de levar a algum tipo de socialismo futuro, foi responsável, ao contrário, pela emergência da atual crise de civilização - confirmada pelos altos índices de destruição ecológica nos países da antiga União das Repúblicas Socialistas Soviéticas (URSS). Não é por acaso, então, que Löwy visualiza em Benjamin uma espécie de precursor do ecossocialismo contemporâneo; ${ }^{9}$ em sua opinião, a crítica benjaminiana da civilização capitalista moderna e do culto ao progresso é um dos temas mais importantes para a construção de uma agenda teórica e política ecossocialista. Nessas críticas estão contidos, como se pôde ver, os elementos para uma crítica da civiliza- 
ção capitalista em suas múltiplas esferas, do trabalho à temporalidade da vida social como um todo.

\section{Ecossocialismo e lutas sociais contemporâneas}

No entanto, mais do que a resposta adequada às exigências teóricas, a possibilidade de constituição de uma perspectiva ecossocialista depende também de condições práticas de possibilidade, que muitas vezes colocam obstáculos à discussão pública entre ecologia radical e socialismo marxista. Muito embora partilhem alguns pontos comuns, 10 o fato é que a articulação e, quiçá, a convergência entre 'vermelhos' e 'verdes' dependem ainda de um difícil trabalho de construção. Se muitos marxistas veem nos movimentos ecológicos tão somente uma expressão da política pós-moderna, que teria mais a confundir do que ajudar, a maioria dos ecologistas, por sua vez, desconfia profundamente do ímpeto produtivista que, para eles, é imanente à abordagem marxista da história como desenvolvimento das forças produtivas do homem.11

Os desafios não são, portanto, dos menores. E a capacidade de enfrentá-los depende de uma abertura mútua entre socialistas e ecologistas radicais. O parâmetro para essa abertura é a compreensão de que crise ecológica e crise social são expressões de uma mesma raiz: o produtivismo capitalista. No primeiro manifesto ecossocialista internacional, redigido a quatro mãos por Michael Löwy e Joel Kovel, afirma-se que “as crises ecológicas e o colapso social estão profundamente relacionados e deveriam ser vistos como manifestações diferentes das mesmas forças estruturais" (apud Löwy, 2005, p. 85). As primeiras derivam "da industrialização massiva, que ultrapassou a capacidade da Terra absorver e conter a instabilidade ecológica" (apud Löwy, 2005, p. 85); já o colapso social decorre "da forma de imperialismo conhecida como globalização, com seus efeitos desintegradores sobre as sociedades que se colocam em seu caminho" (apud Löwy, 2005, p. 85). No limite, “essas forças subjacentes são essencialmente diferentes aspectos do mesmo movimento, devendo ser identificadas como a dinâmica central que move o todo: a expansão do sistema capitalista mundial" (apud Löwy, 2005, p. 85).

Assim, enquanto o marxismo deve acertar contas com a abordagem produtivista do progresso, os ecologistas devem renunciar "às tentações do naturalismo anti-humanista" e abandonar a "sua pretensão de substituir a crítica da economia política", segundo diz Löwy (2005, p. 54); devem ademais, nas palavras de Pierre Rousset, "clarificar sua análise do funcionamento das sociedades humanas e dos meios de transformá-la - o que eles geralmente evitam fazer"12 (2003, p. 212; nossa tradução). Para isso, é imprescindível uma análise sistêmica do capitalismo, a fim de compreender os 
mecanismos cuja reprodução está entre as razões da emergência da crise ecológica. Nesse processo, o marxismo poderia ter algo a contribuir, uma vez que:

Não podemos compreender a crise ecológica que se coloca no horizonte - e que é ao mesmo tempo uma crise de civilização - sem examinar as consequências catastróficas para a natureza da lógica predatória e destrutiva do capital13 (Löwy e Harribey, 2003, p. 5; nossa tradução).

Por sua vez, a ecologia pode ajudar o marxismo em sua ruptura com a temporalidade e a racionalidade abstratas do capitalismo, em direção à compreensão de uma temporalidade qualitativa, contraposta ao imediatismo da lógica mercantil. Pois "a racionalidade limitada do mercado capitalista, com o seu cálculo imediatista de perdas e lucros, é intrinsecamente contraditória com uma racionalidade ecológica, que leve em conta a longa temporalidade dos ciclos naturais" (Löwy, 2005, p. 50).

Não por acaso, os próprios desafios concretos enfrentados pelas várias vertentes das lutas sociais contemporâneas vêm suscitando algumas interessantes aproximações práticas entre enfrentamento social e embate ecológico. As mobilizações sociais e populares contra a mundialização capitalista, desde o Ya Basta! proclamado pela rebelião zapatista em Chiapas, no México, em 1994, e que ganhou novo impulso com os enfrentamentos de Seattle em 1999, caracterizam-se, entre outras coisas, pela importância conferida tanto à dimensão social quanto à dimensão ecológica da luta antissistêmica. Como afirma Löwy:

Hoje, no início do século XXI, a ecologia social se tornou um dos ingredientes mais importantes do vasto movimento contra a globalização capitalista neoliberal que está em processo de desenvolvimento, tanto no norte quanto no sul do planeta. A presença maciça dos ecologistas foi uma das características chocantes da grande manifestação de Seattle contra a Organização Mundial do Comércio em 1999. E no Fórum Social Mundial de Porto Alegre em 2001, um dos atos simbólicos fortes do evento foi a operação, levada a cabo pelos militantes do Movimento dos Sem-Terra brasileiros (MST) e pela Confederação Camponesa Francesa de José Bové, de arrancar uma plantação de milho transgênico da multinacional Monsanto (Löwy, 2005, p. 65).

Uma perspectiva ecossocialista só pode florescer inserindo-se nesses debates e lutas ecossociais, delimitando uma agenda de reflexão e ação anti-capitalista ainda centrada nos trabalhadores e nas classes subalternas como força essencial para qualquer transformação radical do sistema "e para o estabelecimento de uma nova sociedade, socialista e ecológica" (Löwy, 2005, 
p. 47-48). Não se trata da classe social como categoria sociológica ou como mero suporte de uma posição determinada na estrutura de produção, e sim como sujeito que se forma na experiência das lutas ("não há amor sem amantes", dizia E. P. Thompson), as quais vêm revelando um sujeito plural, atravessado por uma diagonal de classes, mas composto também por diversas lutas mais 'específicas', por assim dizer. A articulação política dessas lutas é um dos grandes desafios da constituição de um novo sujeito potencialmente anticapitalista capaz de incorporar e fortalecer a perspectiva ecossocialista. Segundo Michael Löwy:

É um fato que o mundo do trabalho conheceu transformações profundas, principalmente no curso das últimas décadas: declínio do proletariado industrial e desenvolvimento do setor de serviços, desemprego estrutural, formação (notadamente nos países do Terceiro Mundo) de uma massa de excluídos à margem do processo de produção - o 'pobretariado'. (...) Mas o proletariado, no sentido amplo, isto é, aqueles que vivem da venda da sua força de trabalho - ou que tentam vender (os desempregados) - permanece o principal componente da população trabalhadora e o conflito de classe entre o trabalho e o capital continua a ser a principal contradição social das formações capitalistas - assim como o eixo em torno do qual podem se articular os outros movimentos com vocação emancipatória (Löwy, 2000, p. 67).

\section{Crise ecológica e crítica da modernidade em Michael Löwy}

Paradoxalmente, ao mesmo tempo em que exprime as ameaças que pesam sobre a vida humana no planeta, a crise ecológica - como todas as crises - é um momento decisivo, de instabilidade, que pode impulsionar um novo começo, o início ainda indefinido e imprevisível de um projeto ecossocialista (Wolf, 2003, p. 202). Nas crises, a realidade social revela-se em suas múltiplas determinações, e os sujeitos sociais em luta, até então latentes, manifestam seus interesses e perspectivas antagônicas. Trata-se do momento de possibilidade de reabertura da história, momento em que "a política passa à frente da história", como disse Walter Benjamin.

Michael Löwy leva a sério as interpelações da crise ecológica, tomando-a como parâmetro para a renovação do marxismo. Para ele, "a questão ecológica é o grande desafio para uma renovação do pensamento marxista no início do século XXI" (Löwy, 2005, p. 38). A sua reivindicação de uma perspectiva ecossocialista consolida uma trajetória caracterizada - sobretudo a partir da década de 1980 - pela tentativa de radicalizar a crítica marxista do progresso e da modernidade. Estabelecendo uma relação ativa com a herança dos autores do passado, dos clássicos ou hereges da tradição revolucionária, 
Löwy reinterpreta-os à luz das necessidades do presente, redescobrindo virtualidades comumente ignoradas. A principal referência para esse procedimento teórico é, sem dúvida, Walter Benjamin, em cuja obra Michael Löwy encontrou os alicerces para a reinterpretação do marxismo como crítica radical do progresso e da civilização capitalista moderna - ou seja, de questões centrais no debate ecossocialista.

Para Michael Löwy, fundamentalmente, como método de pensamento e de luta - quer dizer, como filosofia da práxis -, o marxismo não só mantém sua atualidade, "mas é o único que pode nos servir de bússola neste confuso e inquietante início do século XXI" (Jinkings e Sader, 2004, p. 16). Para falar como Sartre, o marxismo ainda é, para o intelectual franco-brasileiro, “o horizonte intelectual insuperável de nossa época". Nas palavras de Löwy:

Se a crítica do capital guarda todo o seu valor, é antes de tudo porque a realidade do capitalismo, como sistema mundial, apesar das mudanças inegáveis e profundas que ele conheceu depois de um século e meio, continua a ser aquela de um sistema baseado na exclusão da maioria da humanidade, a exploração do trabalho pelo capital, a alienação, a dominação, a hierarquia, a concentração de poderes e de privilégios, a quantificação da vida, a reificação das relações sociais, o exercício institucional da violência, a militarização, a guerra (Löwy, 2000b, p. 61).

A análise crítica do capitalismo implica porém, para manter a sua eficácia interpretativa, o conhecimento sempre renovado das novas formas de realização do capitalismo. Compreendido, acima de tudo, como uma filosofia da práxis, e não como um sistema teórico abstrato e fechado, um 'marxismo crítico' deve atualizar permanentemente a crítica do capitalismo, 'acompanhando' as transformações do sistema. Desse ponto de vista, a temática do ecossocialismo, ao mesmo tempo em que mobiliza aspectos centrais da obra mais recente de Löwy, permite vincular dialeticamente o constructo teórico do autor à sua reivindicação intelectual e política de um marxismo crítico, renovado e não dogmático, capaz de enfrentar os desafios do mundo contemporâneo.

O ecossocialismo é a demonstração concreta da necessidade de uma ruptura radical do marxismo com o culto moderno ao progresso e com o paradigma civilizatório moderno. É a possibilidade de uma intervenção crítica no debate ecológico, em oposição às diversas formas de 'ecologia de mercado', inclusive aquelas que invocam a tese do 'desenvolvimento sustentável', recusando-se a reconhecer o caráter eminentemente destrutivo e insustentável dos modelos capitalistas de desenvolvimento - fato que se comprova em inúmeros exemplos contemporâneos, tais como o crescimento exponencial da poluição da água, do ar das grandes cidades e do meio 
ambiente em geral, a destruição da biodiversidade e o esgotamento e a desertificação do solo, dentre outros. 14

A crítica ecossocialista desse cenário não hesita em antecipar a possibilidade concreta de um novo modelo de desenvolvimento baseado numa outra relação entre homem e natureza na qual o controle decisório coletivo dissolve o protagonismo aparente das 'leis econômicas' autônomas. 15 Esse pressuposto 'utópico-concreto', como diria Ernst Bloch, longe de enfraquecer a vitalidade da análise teórica, estimula uma crítica que não se contenta em interpretar a catástrofe iminente: busca indicar a possibilidade de sua transposição prática. Na obra de Michael Löwy, a elaboração dessa 'utopia' ecossocialista passa, entre outras coisas, pela releitura do passado a partir da ótica dos vencidos, ou seja, daqueles que resistiram ao progresso hegemônico. Nessa releitura da história auxiliada pela reapropriação crítica dos autores do passado, encontram-se indícios da continuidade, em novas bases, da resistência à destruição capitalista do meio ambiente, indicando a possibilidade de uma nova relação do homem com a natureza e, portanto, consigo mesmo, pois, como disse Marx nos Manuscritos de Paris, de 1844:

Dizer que a vida psíquica e intelectual do homem está indissoluvelmente ligada à natureza não significa outra coisa senão que a natureza está indissoluvelmente ligada com ela mesma, pois o homem é uma parte da natureza (Marx, 2004, p. 84).

Ou, como afirmou Marcuse, tempos mais tarde:

A unidade de homem e natureza ocorre conforme o seu ser: o homem não está na natureza, a natureza não constitui seu mundo externo (...) e sim o homem é natureza; a natureza constitui sua 'exteriorização', 'sua obra e sua realidade'. Onde a natureza sempre chega à história do homem, encontra-se 'natureza humana' enquanto o homem, por um lado, sempre é também já 'natureza humana'. Compreendemos agora, de passagem, até que ponto o 'humanismo' realizado é, imediatamente, 'naturalismo' (Marcuse, 1968, p. 120).

\section{Notas}

1 Doutorando em Sociologia pelo Instituto de Filosofia e Ciências Humanas da Universidade Estadual de Campinas (Unicamp), Campinas, São Paulo, Brasil. $<$ fabiomascaro@yahoo.com.br>

Correspondência: Instituto de Filosofia e Ciências Humanas (IFCH/CPG), Rua Cora Coralina, s/n, CEP 13083-896, Campinas, São Paulo, Brasil. 
2 O primeiro manifesto internacional pode ser encontrado em $<$ www.ecodebate.com.br/pdf/ecossocialismo.pdf $>$, e o segundo em <www.altermundo. org/declaracao-ecossocialista-de-belem-2\%C2\% BA-manifesto-ecossocialista/> .

3 No original: "como uma lucha por el valor de uso y, a través del valor de uso realizado, por el valor intrínseco. Esto significa que es uma lucha por el lado cualitativo de las cosas".

4 No original: "El ecosocialismo es más que el socialismo tal cual se lo conoce tradicionalmente. Pero es también, defintivamente, socialista".

5 "Los estudios históricos marxistas tradicionales que se efectuaram hasta no hace mucho tiempo (...), compartían uma visión de la historia universal y progresista que aunque pretendía criticar el modelo occidental de expansión y el discurso apologético que de allí se desprendía, asumía algunos de sus postulados: el culto a la técnica, la justificación de la destrucción de las culturas locales de las zonas colonizadas por considerar que esa era uma tendencia irreversible, la superioridad de la economía y de la 'cultura' del capitalismo occidental, la subestimación de las capacidades y propuestas de resistencia impulsadas por los pobres y explotados y, en fin, un manifiesto culto de la 'vía única' progresista, fuera de la cual no había escape ni alternativa”' (Vega Cantor, 1999, p. 155).

6 No original: "L'éco-socialisme implique uma radicalisation de la rupture avec la civisation matérielle capitaliste".

7 No original: "restructuration radicale des besoins des hommes et une transformation de la relation aux biens de consommation capable de faire em sorte que la valour d'usage matérielle mette fina au regime de l'échange - em bref, une transformation sociale appelée écosocialisme".

8 Em certa medida, a transformação ecossocialista pode ser concebida como uma "revolução energética", no interior da qual se consubstanciaria "a substituição das energias não-renováveis e responsáveis pela poluição e envenenamento do meio ambiente - carvão, petróleo e combustíveis nucleares - por energias 'leves' e renováveis: água, vento, sol" (Löwy, 2005, p. 55).

${ }_{9}$ A propósito da possibilidade de uma leitura ecossocialista de Walter Benjamin, ver Löwy (2010), e Querido (2010). Isabel Loureiro (2003) desenvolve perspectiva semelhante em sua interpretação do 'marxismo ecológico' de Herbert Marcuse.

10 “O socialismo e a ecologia - ou pelo menos algumas das suas correntes - têm objetivos comuns, que implicam questionar a autonomização da economia, do reino da quantificação, da produção como um objetivo em si mesmo, da ditadura do dinheiro, da redução do universo social ao cálculo das margens da rentabilidade e às necessidades da acumulação do capital. Ambos pedem valores qualitativos: o valor de uso, a satisfação das necessidades, a igualdade social para uns, a preservação da natureza, o equilíbrio ecológico para outros. Ambos concebem a economia como 'inserida' no meio ambiente: social para uns, natural para outros" (Löwy, 2005, p. 42).

11 Para citar apenas um exemplo, ver o comentário de Alain Lipietz, para quem “Marx vê a história como uma 'artificialização' progressiva do mundo, liberando a humanidade dos constrangimentos externos impostos por seu inadequado domínio da natureza" (2002-2003, p. 14). 
12 No original: “clarifier leur analyse du fonctionnement des sociétés humaines et des moyens de le transformer- ce qu'ils évitent généralement de faire".

13 No original: “On ne peut pas comprendre la crise écologique que si profite à l'horizon - et qui est en même temps une crise de civilisation - sans examiner les conséquences catastrophiques pour la nature de la logique prédratrice et destructrice du capital".

14 Nas palavras de Michael Löwy: “Segundo os ecossocialistas, o problema das principais correntes da ecologia política, cujos representantes são os partidos verdes, é que estas não parecem levar em consideração a contradição intrínseca que existe entre a dinâmica capitalista - fundada sobre a expansão ilimitada do capital e a acumulação dos lucros - e a preservação do meio ambiente" (2009, p. 36).

15 Retomando as reflexões de Ernest Mandel, Michael Löwy reivindica o 'planejamento democrático' como mecanismo necessário para uma eventual transição ecossocialista. Diz ele: “Longe de ser 'despótico' em si, o planejamento democrático é o exercício da liberdade de decisão do conjunto da sociedade. Um exercício de 'leis econômicas' e de 'jaulas de ferro' alienantes e reificadas no seio das estruturas capitalistas e burocráticas. O planejamento democrático associado à redução do tempo de trabalho seria um progresso considerável da humanidade em direção ao que Marx chamava de 'o reino da liberdade': o aumento do tempo livre é na realidade uma condição para a participação dos trabalhadores na discussão democrática e na gestão da economia, assim como da sociedade" (Löwy, 2009, p. 39).

\section{Referências}

BENJAMIN, Walter. Eduard Fuchs, collectionneur et historien. In: Oeuvres.

v. 3. Paris: Gallimard, 2000. p. 170-225.

Passagens. Belo Horizonte: Editora UFMG; São Paulo: Imprensa Oficial do Estado de São Paulo, 2006.

Rua de mão única. São Paulo: Brasiliense, 1995.

Sobre o conceito de história. In: Magia e técnica, arte e política. 7. ed. São Paulo: Brasiliense, 1994. p. 222-234.

BENSAÏD, Daniel. Marx intempestivo: grandezas e misérias de uma aventura crítica. Rio de Janeiro: Civilização Brasileira, 1999.

JINKINGS, Ivana; SADER, Emir. Entrevista com Michael Löwy. Margem Esquerda, n. 4, São Paulo, Boitempo Editorial, 2004. p. 9-21.

KOVEL, Joel. El enemigo de la naturaleza: ¿el fin del capitalismo o el fin del mundo? Buenos Aires: Tesis 11, 2005.

Un socialisme pour les temps nouveaux. In: LÖWY, Michael; HARRIBEY, Jean-Marie (Orgs.). Capital contre nature. Paris: PUF, 2003. p. 149-154.

LIPIETZ, Alain. A ecologia política e o futuro do marxismo. Ambiente e Sociedade, Campinas, v. 5, n. 2, v. 6, n. 1, p. 9-22, 2002-2003.

LOUREIRO, Isabel. Le Marxisme écologique de Herbert Marcuse: il faut changer le sens du progrès. In: LÖWY, Michael; HARRIBEY, Jean-Marie (Orgs.). Capital contre nature. Paris: PUF, 2003. p. 155-164. 
LÖWY, Michael. Ecologia e socialismo. São Paulo: Cortez, 2005.

Ecossocialismo e planejamento democrático. Crítica Marxista, São Paulo, n. 28, p. 35-50, 2009.

Luta anticapitalista e renovação do marxismo. Entrevista com Michael Löwy (1998). In: BENSAÏD, Daniel; LÖWY, Michael (Orgs.). Marxismo, modernidade e utopia. São Paulo: Xamã, 2000. p. 248-256.

Por um marxismo crítico. In: BENSAÏD, Daniel; LÖWY, Michael (Orgs.). Marxismo, modernidade e utopia. São Paulo: Xamã, 2000. p. 58-67.

Progrès destructif: Marx, Engels et l'écologie. In: LÖWY, Michael; HARRIBEY, Jean-Marie (Orgs.). Capital contre nature. Paris: PUF, 2003. p. 11-22.

Walter Benjamin critique de la civilisation. Préface. In: BENJAMIN, Walter. Romantisme et critique de la civilisation. Paris: Payot, 2010. Disponível em: <www. europe-solidaire.org/spip.php?article17974>. Acesso em: 20/08/2011.

LÖWY, Michael; HARRIBEY, Jean-Marie. Marxisme et écologie: retour aux sources et rencontre. In: (Orgs.). Capital contre nature. Paris: PUF, 2003. p. 5-8.

LUKÁCS, Georg. História e consciência de classe. São Paulo: Martins Fontes, 2003.

MARCUSE, Herbert. Novas fontes para a fundamentação do materialismo histórico (interpretação dos recém-publicados manuscritos de Marx). In: . Materialismo histórico e existência. Rio de Janeiro: Tempo Brasileiro, 1968. p. 103-159.
MARX, Karl. Manuscritos econômico-filosóficos. São Paulo: Boitempo Editorial, 2004. . Miséria da Filosofia. São Paulo: Centauro, 2001.

QUERIDO, Fabio Mascaro. As utopias indisciplinadas de um marxismo para o século XXI: o marxismo como crítica da modernidade. Entrevista com Michael Löwy. $\mathrm{Lu}$ tas Sociais, São Paulo, v. 21-22, p. 179-185, 2009.

Revolución y (crítica del) progreso: la actualidad ecosocialista de Walter Benjamin. Herramienta, Buenos Aires, n. 43, p. 47-58, mar. 2010.

ROUSSET, Pierre. Crise ecologique, internationalisme et anticapitalisme à l'heure de la mondialisation. In: LÖWY, Michael; HARRIBEY, Jean-Marie (Orgs.). Capital contre nature. Paris: PUF, 2003. p. 203-214.

VEGA CANTOR, Renan. El caos planetario. Ensayos marxistas sobre la miseria de la mundialización capitalista. Buenos Aires: Herramienta, 1999.

WALLERSTEIN, Immanuel. Capitalismo histórico e civilização capitalista. Rio de Janeiro: Contraponto, 2001.

WOLF, Frider Otto. Crise écologique et théorie marxiste. Pour une problématique renouvelée. In: LÖWY, Michael; HARRIBEY, Jean-Marie (Orgs.). Capital contre nature. Paris: PUF 2003. p. 191-202.

Recebido em 05/09/2011

Aprovado em 10/12/2011 